\title{
Oral premalignant lesions: epidemiological and clinical analysis in the northern Polish population
}

\author{
Anna Starzyńska', Anita Pawłowska¹, Dorota Renkielska¹, Igor Michajłowski², Michał Sobjanek², Izabela Błażewicz²
}

${ }^{1}$ Department of Maxillofacial and Oral Surgery, Medical University of Gdansk, Gdansk, Poland

Head of the Department: Prof. Adam Włodarkiewicz MD, PhD

${ }^{2}$ Department of Dermatology, Venereology and Allergology, Medical University of Gdansk, Gdansk, Poland

Head of the Department: Prof. Roman Nowicki MD, PhD

Postep Derm Alergol 2014; XXXI, 6: 341-350

DOI: 10.5114/pdia.2014.40932

\begin{abstract}
Introduction: Leukoplakia is the most common potentially malignant condition of the oral cavity.

Aim: Epidemiological and clinical analysis of patients with oral leukoplakia (OL) diagnosed and treated in the Department of Maxillofacial and Oral Surgery, Medical University of Gdansk.

Material and methods: The study was retrospective and prospective. Among 55911 patients diagnosed and treated in the Department in 1999-2009, 204 people with OL were selected. The material includes 104 women and 100 men with an average age of 58.1. Most of the patients were in the age group of 50-70 years, average age was 58.1. Results: The most common concomitant disease was diabetes. More than $88 \%$ of the patients declared occurrence of OL predisposing development factors (50.49\% - cigarette smoking). Three hundred and twenty foci of OL were found among patients. Homogeneous OL dominated (72.05\%). Multifocal OL was diagnosed in $58.3 \%$ of patients. The most common location of lesions was buccal mucosa (52.2\%). Cancers developed on the basis of OL in 7 patients (3.43\%). The percentage of malignant transformation was $12.19 \%$ for untreated patients and $1.41 \%$ for treated patients. The floor of the oral cavity was proven to be the location of the highest risk of oral squamous cell carcinoma. Patients with diabetes may be more likely to develop OL. The risk of malignant transformation is relatively high. In our material it was equal to $3.43 \%$.

Conclusions: Cigarette smoking is the most important factor, which can influence the effectiveness of treatment.
\end{abstract}

Key words: leukoplakia, oral premalignant lesion, epidemiology.

\section{Introduction}

Potentially malignant diseases of the oral mucosa, with the risk of conversion to squamous cell carcinoma (oral squamous cell carcinoma-OSCC), are described in the literature as 'pre-cancer', 'precursor lesions', 'premalignant', 'intraepithelial neoplasia', and 'potentially malignant'. At the moment, according to the World Health Organization (WHO), lesions and conditions of the oral mucosa, which may undergo malignant transformation are defined as a potentially malignant disorder (PMD) [1]. Early diagnosis and implementation of appropriate treatment of PMD is crucial in preventing OSCC. There are 5 conditions described as potentially malignant disorders - erythroplakia, lichen planus, oral submucosus fibrosis, actinic cheilitis and leukoplakia. The term 'erythroplakia of the oral mucosa' (oral erythroplakia - OE) describes red discs, which in a clinical and histopathological examination, do not correspond to any defined disease [2]. The OE may resemble many diseases of the oral cavity such as candidiasis, tuberculosis, histoplasmosis, pemphigus, amelanotic melanoma and Kaposi's sarcoma. The OE occurs in $0.02-0.83 \%$ of the population, usually among elderly and middle-aged men. The clinical picture of OE includes well-demarcated red discs with a smooth or granular surface. Sometimes concave changes can be observed, rarely nodular lesions are present. The soft palate, floor of the mouth and buccal mucosa are reported to be the most frequent locations of OE. Aetiology and pathogenesis of OE are not fully recognised. It is assumed that a significant number of OE cases are associated with cigarette smoking, tobacco chewing and alcohol abuse [3-5]. Histopathology reveals atrophic

Address for correspondence: Anna Starzyńska MD, PhD, Department of Maxillofacial and Oral Surgery, Medical University of Gdansk, 17 Smoluchowskiego St, 80-214 Gdansk, Poland, phone: +48 505167 428, fax: +48 583 493 100, e-mail: ast@gumed.edu.pl Received: 14.07.2013, accepted: 18.09.2013. 
stratified epithelium; features of dysplasia or squamous cell carcinoma can be present. The percentage of neoplastic transformation of OE ranges from $14 \%$ to $50 \%$ [6]. Surgical removal of the lesions seems to be the most effective treatment. Cryosurgery or laser therapy may be useful in the treatment of OE without presence of dysplasia or with low-grade dysplasia. The incidence of oral lichen planus (OLP) is estimated at 0.4-2.5\%. The clinical picture includes reticulate, papular, plaque-like, erosive, atrophic and bullous lesions. Polymorphic eruptions can often occur. Malignant transformation of OLP is recorded in $1 \%$ of cases; the development of OSCC is more likely to occur in erosive, atrophic and plaque-like lesions [7]. The mechanism of malignant transformation remains unknown. Induced therapy depends on the presence or absence of dysplasia. Oral submucous fibrosis (OSF) occurs in Southern Asia. Lesions in the course of OSF are associated with chewing areca nut and betel palms. Alkaloids present in the seeds, which affect the deposition and degradation of collagen, are crucial in pathogenesis of OSF. Neoplastic transformation is recorded in $0.5 \%$ of cases [8]. Actinic cheilitis (AC) is observed more often in elderly men with fair skin (I and II skin phototype), who are particularly exposed to ultraviolet radiation $[9,10]$. In the initial stage of the disease, redness and swelling of the lips with desquamation of the epithelium can occur. Over time, erosions and scrub covered ulcers may develop. Choice of appropriate treatment depends on the result of histopathological examination. Leukoplakia is the most common potentially malignant lesion within the oral epithelium. The name derives from Greek and is a combination of the words: $\lambda \varepsilon v \chi_{0}$ (leuko - white) and $\pi \lambda \alpha \kappa o \sigma$ (plakos - patch). Oral leukoplakia $(\mathrm{OL})$ is defined as a white shield with an uncertain risk of malignant transformation by excluding other known diseases or disorders that are not connected with an increased risk of cancer [11]. The $\mathrm{OL}$ is a clinical term made by exclusion. It does not have a characteristic histopathological picture, there are no references to the presence or absence of dysplasia. The term 'leukoplakia' is used as a clinical or histopathological term. Leukoplakia occurs in a population with a frequency of $0.2-11.7 \%$ and is subject to geographic and ethnic variations. The average global incidence rate is estimated at around 2\% [12]. The average age of patients with $\mathrm{OL}$ is 60 years old and is close to the average age of patients with oral cancer. Men suffer from OL three times more often than women, although among young patients the ratio is $1: 1$. Nevertheless, there are also reports of more frequent occurrence among women [13]. This might be associated with a higher prevalence of smoking among women compared to the past decades. Aetiology of OL is still not fully recognised. Local predisposing factors include chemical factors (tobacco, alcohol) - which are crucial ones, mechanical factors (chronic trauma), thermal factors (burns after eating hot food) and electrogalvanic (burns resulting from the local elec- trical potential difference between metals present in the oral cavity), UV radiation, viral infections (human papillomavirus), bacterial and fungal infections (chronic candidiasis). Systemic predisposing factors include hormonal imbalance, excessive secretion of the gastric juice, diabetes, decreased salivation, Plummer-Vinson syndrome and vitamin deficiencies [14]. The endogenous and exogenous OL development factors mentioned above should be treated more as promotion than causal ones. In about $14 \%$ of patients with OL no obvious reason for the disease can be found. Clinically there are two types of $\mathrm{OL}$ : homogenous (includes flat, white coloured changes) and non-homogenous (includes white and red coloured lesions (erythroleukoplakia) as well as verrucous leukoplakia where white coloured and uneven surface dominate). A subtype of verrucous leukoplakia is proliferative verrucous leukoplakia, which is characterized by multifocal lesions, resistance to treatment and frequent conversion into OSCC (70\%) [15]. Over 2/3 of all changes are present in three locations: the lips, buccal mucosa and gingiva [16] and are usually localized on mucous membrane near the occlusal surfaces of lateral teeth (Kiesow zone), often symmetrically. Lesions located on the gums include the entire surface of toothless alveolar or are linear, often separated from the alveolar rim. The OL occurs much less frequently on the lower surface of the tongue and the floor of the mouth. However, in these places dysplasia often coexists, which in consequence leads to malignant transformation of such lesions. To date, the classification of OL proposed by van der Waal has been used [17]. It includes the size of OL, its clinical picture (homogenous/non-homogenous) and histopathology (presence/absence of dysplasia) (Table 1). Large, non-homogenous lesions with dysplasia are more likely to undergo malignant transformation.

The presence and severity of dysplasia are based on an assessment of architectural abnormalities and atypia of cells. The main dysplasia classifications are the WHO classification system, squamous intraepithelial neoplasia (SIN) system, Ljubljana classification of squamous intraepithelial lesions. According to WHO, low-grade dysplasia (mild dysplasia) determines the changes which involve only the lower $1 / 3$ epithelium thickness, moderate dysplasia corresponds to the occupation of the epithelium in 2/3 of its thickness, highgrade dysplasia (severe dysplasia) is diagnosed when abnormal cells are located in the superficial layers of the epithelium (more than two thirds of epithelium). Carcinoma in situ means that the entire thickness of epithelium is involved. The stage of dysplasia remains a largely subjective assessment of the pathologist examining the preparation and depends on the condition of the section and its technical processing. According to SIN classification of squamous intraepithelial neoplasia, there are three types of changes. In comparison to the WHO staging, SIN 1 corresponds to low-grade dysplasia, SIN 2 applies to moderate dysplasia, SIN 3 includes 
both high-grade dysplasia and carcinoma in situ. The histological classification of epithelial proliferative lesions of Ljubljana includes benign and premalignant lesions. Benign lesions include simple hyperplasia and abnormal hyperplasia. The premalignant changes consist of two groups: atypical hyperplasia with features of stimulation, which has a low risk of malignant transformation and carcinoma in situ, which has a high risk of malignant transformation. The presence of non-homogenous leukoplakia in a clinical trial, and dysplasia in the histopathological examination remain the most significant risk factors for malignant transformation, which ranges from $0.13 \%$ to $17.5 \%$. The average annual rate of malignant transformation in Western countries for all types of OL is assumed at 1\% [11]. The probability of dysplasia or carcinoma correlates with the appearance of macroscopic changes. Nodular leukoplakia and especially verrucous leukoplakia, have a higher risk of developing dysplasia than homogeneous leukoplakia in the early stages of development. Transition into invasive squamous cell carcinoma is the most probable in proliferative verrucous leukoplakia. According to various authors, the frequency of malignant transformation varies between $70 \%$ and $100 \%$ [18]. The choice of treatment method depends on the clinical stage of OL, presence or absence of dysplasia in histopathological examination. In the case of initial clinical diagnosis of OL (suspicion of leukoplakia), the therapeutic procedure aims to eliminate the possible causative factors (removal of mechanical and chemical injuries, cessation of tobacco and alcohol consumption, correction of various irregularities in biochemistry examination). A 2-4-week period of observation is necessary. In absence of improvement during the observation period and in patients with OL without any etiological factors, histopathological diagnosis should be performed. The choice of treatment depends on absence or presence of dysplasia. Dysplasia entitles to surgical treatment.

The main purpose of this study was epidemiological and clinical analysis of patients with oral leukoplakia diagnosed and treated in the Department of Maxillofacial and Oral Surgery, Medical University of Gdansk and determining the risk of squamous cell carcinoma development in patients with oral leukoplakia.

\section{Aim}

Leukoplakia is the most common potentially malignant condition of the oral cavity. An increasing number of oral cancer cases, low social awareness and therapeutic difficulties resulted in clinical and epidemiological research. The main purpose of this study was epidemiological and clinical analysis of patients with OL diagnosed and treated in the Department of Maxillofacial and Oral Surgery, Medical University of Gdansk.
Table 1. Classification of OL according to van der Waal

\begin{tabular}{|c|c|c|c|c|}
\hline \multirow{4}{*}{\multicolumn{2}{|c|}{$\begin{array}{l}\mathrm{L} \\
\text { Size of OL }\end{array}$}} & L1 & \multicolumn{2}{|c|}{ Lesion $\leq 2 \mathrm{~cm}$} \\
\hline & & L2 & \multicolumn{2}{|c|}{ Lesion of $2-4 \mathrm{~cm}$} \\
\hline & & L3 & \multicolumn{2}{|c|}{ Lesion $\geq 4 \mathrm{~cm}$} \\
\hline & & Lx & \multicolumn{2}{|c|}{ Size of lesion not specified } \\
\hline \multirow{3}{*}{\multicolumn{2}{|c|}{$\begin{array}{l}\text { P } \\
\text { Histopathological } \\
\text { picture }\end{array}$}} & PO & \multicolumn{2}{|c|}{ No dysplasia } \\
\hline & & P1 & \multicolumn{2}{|c|}{ Dysplasia } \\
\hline & & PX & \multicolumn{2}{|c|}{$\begin{array}{l}\text { Presence of dysplasia not } \\
\text { specified }\end{array}$} \\
\hline \multirow{2}{*}{\multicolumn{2}{|c|}{$\begin{array}{l}\text { C } \\
\text { Clinical presentation }\end{array}$}} & $\mathrm{C} 1$ & \multicolumn{2}{|c|}{ Homogenous leukoplakia } \\
\hline & & $C 2$ & \multicolumn{2}{|c|}{ Non-homogenous leukoplakia } \\
\hline $\begin{array}{c}\text { Stage } \\
\text { of } \\
\text { leukoplakia }\end{array}$ & \multicolumn{3}{|c|}{$\begin{array}{c}\text { Evaluation } \\
\text { of leukoplakia based } \\
\text { on histopathological } \\
\text { examination }\end{array}$} & $\begin{array}{c}\text { Evaluation } \\
\text { of leukoplakia } \\
\text { based on clinical } \\
\text { manifestation }\end{array}$ \\
\hline 1 & \multicolumn{3}{|c|}{ L1, PO } & $\mathrm{L} 1, \mathrm{C} 1$ \\
\hline II & \multicolumn{3}{|c|}{$\mathrm{L} 2, \mathrm{PO}$} & $\mathrm{L} 2, \mathrm{C} 1$ \\
\hline III & \multicolumn{3}{|c|}{ L3, P0, L1, L2, P1 } & L3, C1, L1, L2, C2 \\
\hline IV & \multicolumn{3}{|c|}{ L3, P1 } & $\mathrm{L} 3, \mathrm{C} 2$ \\
\hline
\end{tabular}

\section{Material and methods}

The study was performed at the Department of Maxillofacial and Oral Surgery, Medical University of Gdansk (Head of the Department Professor Adam Włodarkiewicz) in 2005-2009. Among 55911 patients diagnosed and treated in the clinic in 1999-2009, 204 people with OL were selected. The material includes 104 women and 100 men with the average age of 58.1 years. The study was retrospective and prospective. In the retrospective part, epidemiological and clinical evaluation of the treatment of patients, who were diagnosed and treated between 1999 and 2004 was performed. However, in this period of time patients with OL were treated with cryosurgery and surgery. Prospective studies were conducted in 2005-2009. At that time, besides the above-mentioned therapies, topical $0.05 \%$ tretinoin cream was applied. In each case of OL, the diagnosis was confirmed by histopathological examination. Each patient carried out sanitation of the oral cavity in order to eliminate factors sustaining the disease. The clinical diagnosis involved WHO criteria for potentially malignant disorders and the classification of leukoplakia by Axell and fourstage classification of van der Waal. The moment when changes occur was defined; special attention was paid to risk factors, medications and chronic diseases. Photographic documentation was performed using a digital camera (Kodak). A full course of therapy and follow-up period over 6 months was completed by 178 patients (87.25\% qualified for treatment). In the case of failure or relapse of $\mathrm{OL}$ after topical $0.05 \%$ tretinoin treatment, cryosurgery or surgery was performed. Relapse after 
cryosurgery treatment was treated again with cryosurgery or was surgically removed. These results relate to the treatment of 178 cases. Treatment with a cream containing $0.05 \%$ tretinoin (Locacid, Pierre-Fabre) was used in 74 cases. Patients used the topical cream on the affected area twice a day. They prolonged its contact with the mucous membrane acting with an occlusive swab or spatula. In the case of irritation, smearing 5\% Solcoseryl paste (ICN Polfa Rzeszow) or stopping the application for 24-48 h were recommended. Topical treatment was used for at least 8 weeks. Cryosurgery was performed in 63 patients. All procedures were performed under local anaesthetic infiltration of $2 \%$ lignocaine using Cryo-S engine with nitrous oxide as a cooling medium. All procedures were performed by spraying, using two cycles of freezing of $40 \mathrm{~s}$ each, with an interval of 2-3 min between them. In the case of multifocal changes, multistep treatment with 2-3 weeks' interval between the visits was taken. In the case of pain, over-the-counter nonsteroidal anti-inflammatory drugs and $5 \%$ Solcoseryl paste (ICN Polfa Rzeszow) were recommended after the surgery. Forty-one patients underwent surgical treatment. The surgeries were performed under local anaesthetic infiltration of $2 \%$ lignocaine with noradrenaline. Excisions were performed within borders of clinically visible changes. Depending on the location and size of the lesions, cavities were closed in a linear way, covered with a graft or allowed to cover with granulation tissue. Patients were monitored at 2, 4, 6 and 8 weeks and then every 6 months. No significant side effects or complications during the treatment which could interrupt the therapy were observed. Recuperation was assumed when changes clinically subsided. Partial regression was assumed for relief of at least $50 \%$ of the changes. Other changes were classified as no improvement/relapse. The appearance of new lesions in the adjacent area was regarded as a relapse.

\section{Statistical analysis}

All calculations were performed using the statistical package Statistica 8.0 (StatSoft, Inc. In 2008), and Microsoft Excel 2003. To assess the statistical significance of differences in the results, $\chi^{2}$ tests were used (depending on the size of the samples and the expected numbers an original method of Pearson, test with Yate's correction or Fisher's exact test were used). In all statistical tests, the level of statistical significance was $p<0.05$.

\section{Results}

Among 55911 patients, lesions clinically resembling OL (manifested as white spots or discs) were observed in 256 patients (4.35\%). Among these 256 patients, the diagnosis was the following: leukoplakia in 204 patients (79.69\%), reactive keratosis - 29 (11.33\%), lichen planus - 10 (3.91\%), candidiasis - 9 (3.52\%), and squamous cell carcinoma - 4 (1.56\%). The reactive keratosis was usually associated with biting mucous membrane or friction (Figure 1). In these cases, recovery occurred after removal of irritants.

In 4 cases (1.56\%), histological examination revealed squamous cell carcinoma (Figure 2). The OL was diagnosed in 204 people. Table 2 shows the age and sex distribution of patients with OL. Over $63 \%$ of the patients were in the age group of 50-70 years. The average age was 58.1 (59.4 for women and 56.7 for men).

Ninety-four patients (46.08\%) reported concomitant diseases. The most common disease was diabetes -24 patients (11.76\%). Factors predisposing to the development of OL were reported by 181 patients (88.72\%), while cigarette smoking was the most common factor (50.49\%) (Table 3). In patients younger than 40 years old, the percentage of smokers was $88.88 \%$.

In 204 patients, 320 foci of OL were found. Homogenous leukoplakia (Figure 3) was noted in 147 patients
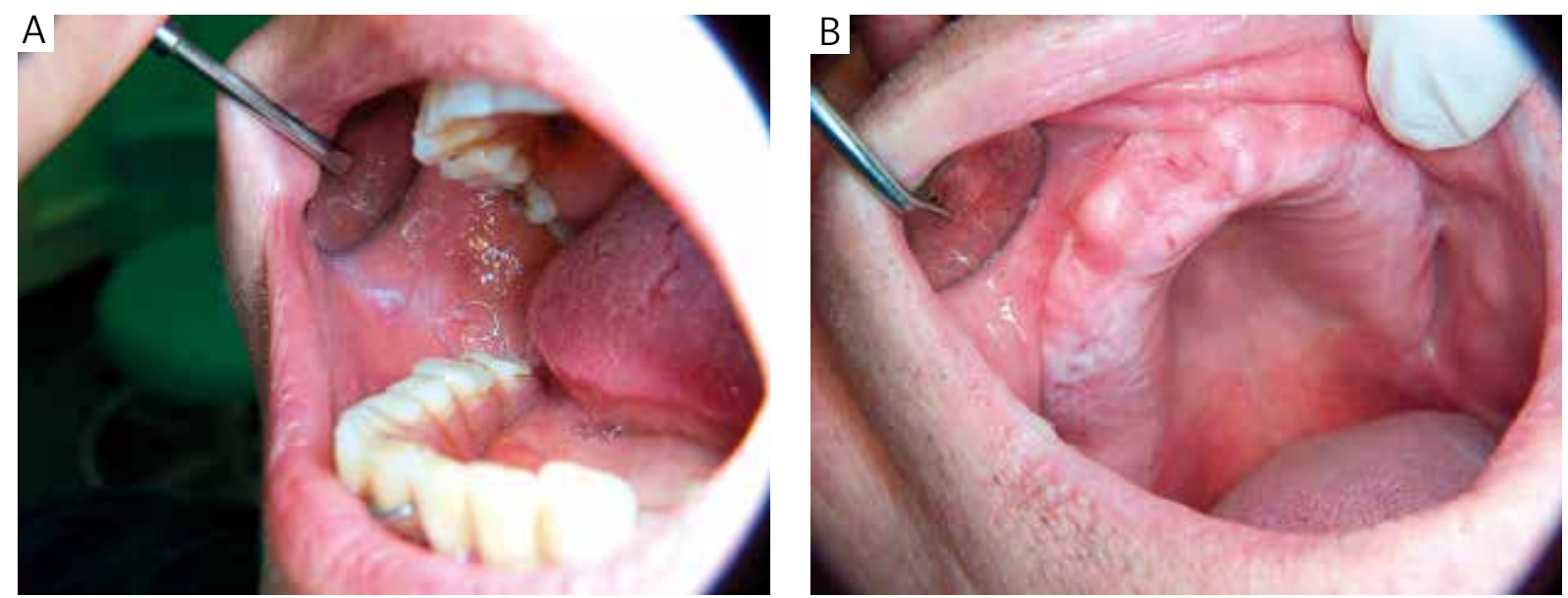

Figure 1. Reactive keratosis caused by biting (A) and friction (frictional keratosis) - toothless gums (B) 
(72.05\%), non-homogenous leukoplakia (Figure 4) in 57 patients (29.95\%). In 85 (41.7\%) patients, there was unifocal leukoplakia (Figure 5), multifocal leukoplakia (Figure 6) in 119 patients (58.3\%).

The most common location of the lesions was buccal mucosa (52.2\%). Table 4 shows the distribution of changes location. Lesions localized on the lip occurred significantly more often in men $(p=0.05)$.

According to van der Waal's classification, the largest group of patients was classified into stage I and II. In 7 cases, the presence of dysplasia was noted (including 2 with a high grade dysplasia) (Tables 5, 6).

Cancers developed on the basis of OL were diagnosed in 7 patients (3.43\%) (Figures 7-9). In 5 cases, these were patients who did not start or discontinued treatment (26 patients), whereas in 2 cases, the treatment was ineffective. In most cases, the reason for the next medical consultation were pain and burning sensation associated with food intake. The percentage of malignant transformation of OL into OSCC was $12.19 \%$ in patients who gave up therapy. In treated and systematically observed patients the percentage of transformation was $1.41 \%$.

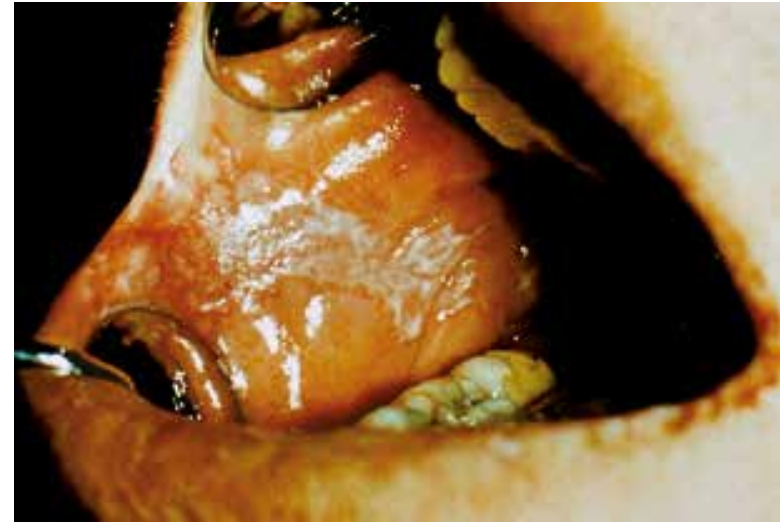

Figure 2. The SCC is manifested as white disks and patches within the buccal mucosa

The highest percentage of malignant transformation was noted for lesions situated on the floor of the mouth (13.3\%). Table 7 shows information about patients including the location of OL within which OSCC developed (Figures 7-9).

Table 2. Distribution of age and gender of the patients with OL

\begin{tabular}{lcccccccc}
\hline Gender & \multicolumn{9}{c}{ Age } \\
\cline { 2 - 8 } & $\mathbf{2 0 - 3 0}$ & $\mathbf{3 1 - 4 0}$ & $\mathbf{4 1 - 5 0}$ & $\mathbf{5 1 - 6 0}$ & $\mathbf{6 1 - 7 0}$ & $\mathbf{7 1 - 8 0}$ & $\mathbf{8 1 - 9 0}$ & Total \\
\hline Female & $2(1.0 \%)$ & $6(2.9 \%)$ & $10(4.9 \%)$ & $38(18.6 \%)$ & $30(14.7 \%)$ & $12(5.9 \%)$ & $6(2.9 \%)$ & 104 \\
\hline Male & $2(1.0 \%)$ & $8(3.9 \%)$ & $17(8.3 \%)$ & $37(18.1 \%)$ & $24(11.8 \%)$ & $10(4.9 \%)$ & $2(1.0 \%)$ & 100 \\
\hline Total & $4(2.0 \%)$ & $14(6.9 \%)$ & $27(13.2 \%)$ & $75(36.7 \%)$ & $54(26.5 \%)$ & $22(10.8 \%)$ & $8(3.9 \%)$ & 204 \\
\hline
\end{tabular}

Table 3. Distribution of factors predisposing to the development of OL

\begin{tabular}{lccccc}
\hline Gender & Cigarettes & Alcohol & Trauma & Spices & Prosthesis \\
\hline Female & $59(28.92 \%)$ & $50(24.51 \%)$ & $29(14.22 \%)$ & $13(6.37 \%)$ & $24(11.76 \%)$ \\
\hline Male & $44(21.57 \%)$ & $33(16.18 \%)$ & $30(14.71 \%)$ & $11(5.39 \%)$ & $17(8.33 \%)$ \\
\hline Total & $103(50.49 \%)$ & $83(40.69 \%)$ & $59(28.93 \%)$ & $24(11.76 \%)$ & $41(20.09 \%)$ \\
\hline
\end{tabular}

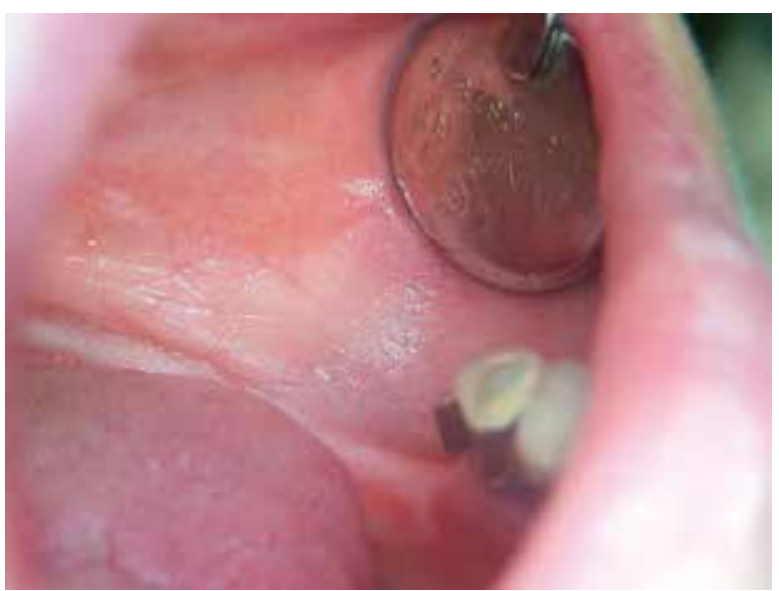

Figure 3. Clinical manifestation of homogeneous leukoplakia of buccal mucosa

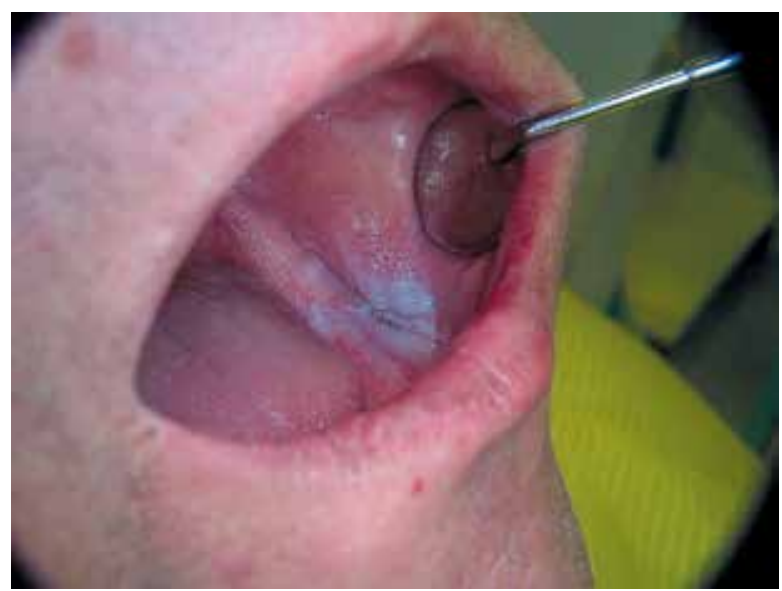

Figure 4. Heterogeneous leukoplakia of buccal mucosa 


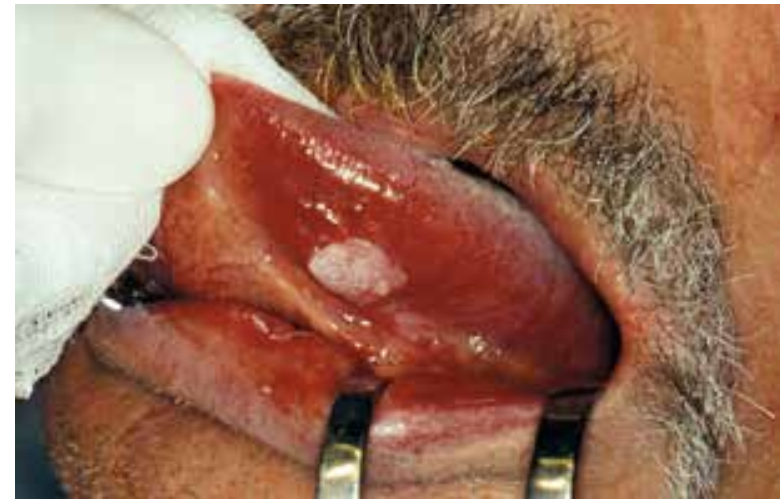

Figure 5. Unifocal OL of the tongue

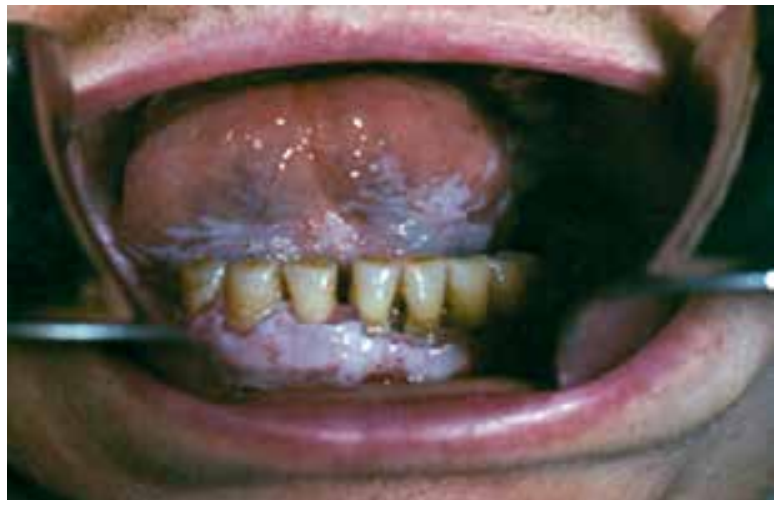

Figure 6. The clinical manifestation of multifocal OL

Table 4. Distribution of changes location

\begin{tabular}{lcccccccc}
\hline Gender & Cheek & Tongue & Floor of the mouth & Lower gum & Upper gum & Lip & Palate & Diffused \\
\hline Female & $91(28.4 \%)$ & $12(3.8 \%)$ & $21(6.6 \%)$ & $33(10.3 \%)$ & $13(4.1 \%)$ & $3(0.9 \%)$ & $5(1.6 \%)$ & $1(0.3 \%)$ \\
\hline Male & $76(23.8 \%)$ & $8(2.5 \%)$ & $9(2.8 \%)$ & $28(8.8 \%)$ & $9(2.8 \%)$ & $8(2.5 \%)$ & $2(0.6 \%)$ & $1(0.3 \%)$ \\
\hline Total & $167(52.2 \%)$ & $20(6.3 \%)$ & $30(9.4 \%)$ & $61(19.1 \%)$ & $22(6.9 \%)$ & $11(3.4 \%)$ & $7(2.2 \%)$ & $2(0.6 \%)$ \\
\hline
\end{tabular}

Table 5. Distribution of OL according to the classification of van der Waal on the basis of the clinical picture

\begin{tabular}{lcccc}
\hline Gender & I & II & III & IV \\
\hline Female & $94(29.4 \%)$ & $44(13.8 \%)$ & $36(11.3 \%)$ & $5(1.6 \%)$ \\
\hline Male & $64(20.0 \%)$ & $31(9.7 \%)$ & $42(13.1 \%)$ & $4(1.3 \%)$ \\
\hline Total & $158(49.4 \%)$ & $75(23.5 \%)$ & $78(24.4 \%)$ & $9(2.9 \%)$ \\
\hline
\end{tabular}

Table 6. Distribution of leukoplakia according to the classification of van der Waal on the basis of the histological picture

\begin{tabular}{|c|c|c|c|c|}
\hline Gender & I & II & III & IV \\
\hline Female & 106 (33.1\%) & 53 (16.6\%) & 19 (5.9\%) & $1(0.3 \%)$ \\
\hline Male & 86 (26.9\%) & 42 (13.1\%) & $13(4.1 \%)$ & $0(0.0 \%)$ \\
\hline Total & 192 (60.0\%) & 95 (29.7\%) & $32(10.0 \%)$ & $1(0.3 \%)$ \\
\hline
\end{tabular}

\section{Discussion}

Leukoplakia, the most common pre-cancerous condition of the oral cavity, is quite often the subject of research investigations. According to the literature, OL affects from $0.2 \%$ to $11.7 \%$ of the population [19]. Such significant differences are due to dissimilarities in the incidence of pathology in the defined age, ethnic and social group. Axell [20] conducted epidemiological studies on a group of 20333 Swedes aged over 15 years old; OL was found in $3.6 \%$ of patients. In the Dutch material of Hogewind and van der Waal [21], the percentage was 1.4\% (1000 patients). In the Italian material of Campisi et al. [22], OL was diagnosed in $13.8 \%$ of men over 40 years old. Cebeci et al. [23], after analysing the results of 5000 routine dental examinations, diagnosed OL only in $0.4 \%$ cases. Tokajuk et al. [24] conducted an epidemiological research in the north-east region of Poland. Among 591 patients aged over 55, OL was diagnosed in 7.4\% of cases. In a study of Knychalska-Karwan [25], OL was detected in $5.75 \%$ of the patients aged $15-80$ years old. The presented differences are due to at least two reasons. First, the analysis relates to different age groups. Secondly, because of the nonspecific clinical manifestation, some of mucosal abnormalities, in which dysplasia is never or very rarely present, are included in OL. In the recent years, there has been a tendency to exclude these changes from the group of leukoplakia. Unfortunately, in practice this is not always possible. Some authors believe 


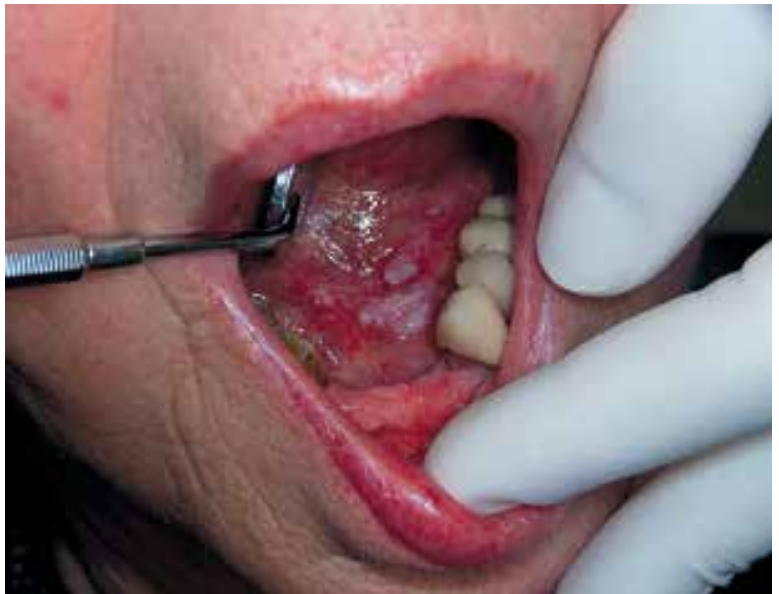

Figure 7. OSCC in situ (TISNO) - the floor of the mouth growing on the basis of $\mathrm{OL}$ (patient 2)

that changes like reactive keratosis may constitute up to half of all the pathologies of the oral mucosa [18, 26, 27]. In our material, these changes were observed in $11.33 \%$ of patients. The literature emphasizes a three times higher incidence of OL in men; in the material of Cebeci et al. [23], the male to female ratio was $4: 1$. Our own results, as well as other Polish reports, do not confirm this information; the male to female ratio was $1: 1$ [13]. The reason for such a ratio might be a high percentage of smoking women in Poland as well as their higher health awareness. Results relating to the age of patients are similar to these in the literature [13]. More than $76 \%$ of patients were over 40 years old - the average age was 58 years. In the age group under 50 years, predominance of women was observed. Bouquot [28], after analysing 23616 white Americans, diagnosed OL in $8 \%$ of men and $2 \%$ of women over 70 years old. In the material of Bizon-Wróblewska et al. [29], in patients over 30 years old, OL was the second most common (after lichen planus) disease of the oral mucosa. While in patients in the age group of $40-50$ years, it was the dominant change. The impact of smoking on the incidence of $\mathrm{OL}$ is now indisputable. In Hungarian studies, the percentage of smokers was $82-100 \%$ [30]. Morger et al. [31], in a study of 615 Swiss army recruits, showed a statistically higher incidence of pathology of the oral mucosa, including OL, among smokers and alcohol abusers. Depending on the social habits related to the use of tobacco, there is a connection between $\mathrm{OL}$ and smoking pipes and cigars, chewing black tobacco, betel. It is assumed that about $30 \%$ of the Polish society is addicted to cigarette smoking [32, 33]. In our study, smokers constituted more than $50 \%$ of patients. In the group of patients under 40 years old, this percentage was $80 \%$. Apart from the fact of smoking, the number of smoked cigarettes is important. Banoczy and Rigo [34] assume that among 104 patients with OL, 13.5\% did not smoke, $9.6 \%$ smoked 10 cigarettes per day while

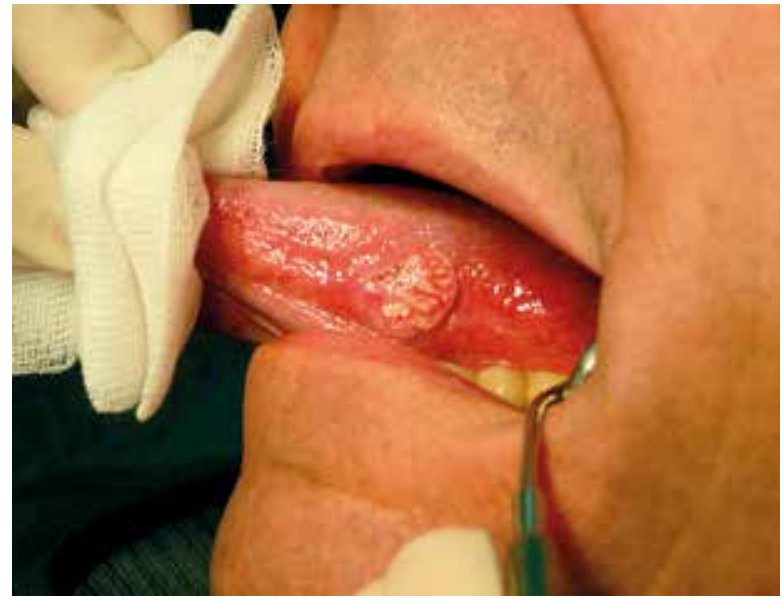

Figure 8. OSCC of the tongue (T2N1) growing on the basis of OL (patient 7)

$76.9 \%$ more than 10 cigarettes. Alcohol abuse, especially high percentage alcohol, is also a predisposing factor for $\mathrm{OL}$ and oral cancer. It is believed that in the carcinogenesis process tobacco acts both at the initiation and promotion stage, however alcohol only acts at the promotion stage. Carcinogenic effects of these two factors do not add up, but multiply [33]. The role of alcohol as an independent factor for OL and OSCC development is not as well documented as tobacco. In 2006, Maserejian et al. [35] conducted a prospective study among 41458 people and proved that the risk of developing $\mathrm{OL}$ is dependent on the amount of alcohol regardless of the tobacco. The proposed mechanism of alcohol action involves a direct effect on the mucous membrane (facilitating penetration of carcinogens, action causing atrophy) and systemic (immunosuppression, damage of liver detoxification function, mutagenic action of its metabolites). In our

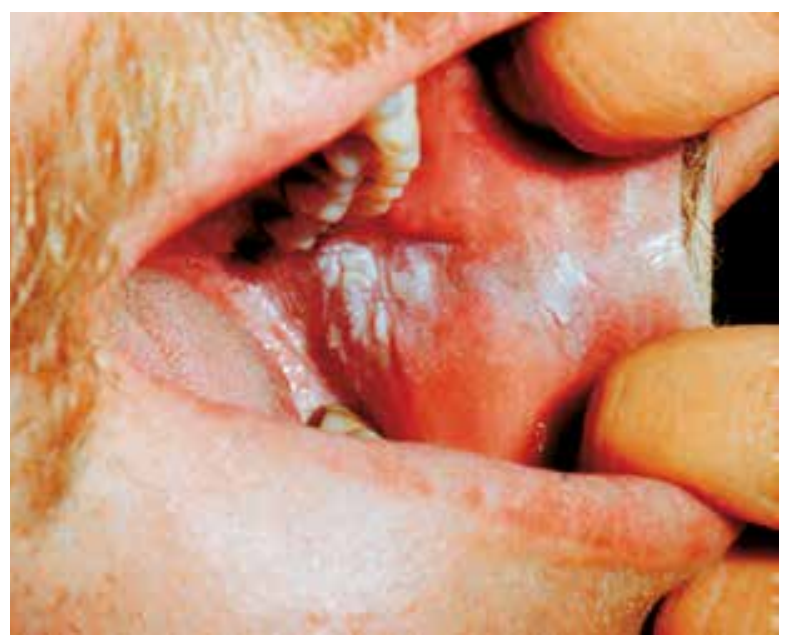

Figure 9. OSCC of buccal mucosa (T2N1) growing on the basis of OL (patient 5) 
Table 7. Information about seven patients diagnosed with OSCC developing on the basis of OL. Treated and systematically observed patients are marked bold

\begin{tabular}{cccccccccc}
\hline No. & Gender & Age & $\begin{array}{c}\text { Location } \\
\text { of OL/SCC }\end{array}$ & $\begin{array}{l}\text { Van der } \\
\text { Waal }- \\
\text { clinical }\end{array}$ & $\begin{array}{c}\text { Van der } \\
\text { Waal } \\
\text { histological }\end{array}$ & $\begin{array}{c}\text { Smoking } \\
\text { diagnosis of } \\
\text { OL and SCC } \\
\text { [years] }\end{array}$ & $\begin{array}{c}\text { Histological } \\
\text { type } \\
\text { of cancer }\end{array}$ & $\begin{array}{c}\text { Stage of } \\
\text { cancer }\end{array}$ \\
\hline 1 & F & 59 & FM & III & II & + & 5 & SCC G2 & T2N1 \\
\hline 2 & F & 63 & FM & III & II & + & 2 & $\begin{array}{l}\text { SCC G2 } \\
\text { (in situ) }\end{array}$ & TISNO \\
\hline 3 & F & 54 & FM & III & III & + & 6 & SCC G1 & T2N1 \\
\hline 4 & F & 66 & FM & III & II & + & 3 & SCC G2 & T1N0 \\
\hline 5 & M & 54 & C & II & II & + & 5 & SCC G2 & T2N0 \\
\hline 6 & M & 55 & L & II & II & + & 4 & SCC G1 & T2N0 \\
\hline 7 & M & 62 & T & II & II & + & 6 & SCC G2 & T2N1 \\
\hline F-female, M- male, FM-floor of the mouth, C-cheek, L-labia, T-tongue & & & &
\end{tabular}

study, more than $40 \%$ of patients admitted to alcohol drinking more than twice per week. It is estimated that about $16 \%$ of the population in Poland abuse alcohol. The results connected with coexisting diseases, especially diabetes are very interesting from a clinical point of view. It is assumed that about $5 \%$ of the Polish society is suffering from this disease. In our study this percentage is much higher. Our observations confirm the hypothesis of some researchers that the development of diabetes predisposes to OL. Albrecht et al. [36] proved a high prevalence of $\mathrm{OL}$ in diabetics in comparison with a control group (6.2\% vs. 2.2\%). Dietrich et al. [14] demonstrated that patients with diabetes have a twice higher risk of OL development compared with the healthy population. The pathomechanism of OL formation in diabetics is probably associated with the weakening of the protective role of mucous membrane due to its atrophy, reduced secretion of saliva and $\mathrm{pH}$ reduction. It should be noted that the elevated blood glucose level increases the amount of free radicals and reduces antioxidant potential of tissues [37] Other factors which play a potential role in the aetiology of OL include nutritional deficiencies (especially vitamins), hormonal disorders, chronic injury and inflammations [38, 39]. Our results have proven the role of chronic injuries that have been demonstrated in more than $28 \%$ of patients and were often associated with dysfunctional prosthesis. In our study homogenous leukoplakia dominated $(72 \%)$, what is compatible with other reports [13, 20, 21]. The most common location was the cheek mucosa as well, as in Petkowicz's (60.4\%) [13] and other authors' studies [40]. From the clinical point of view, the connection between $\mathrm{OL}$ and oral cancer is the most important. It is estimated that about $50 \%$ of oral squamous cell carcinomas develop on the basis of OL $[18,33]$. This fact is extremely important because of oral cancer prevention. Unfortunately, little attention is paid to the prevention of this disease, in contrast to breast, prostate, uterine and colon cancer. This seems to be an inappropriate approach since the oral cancer is the eighth most common cancer in Poland and accounts for $2.5 \%$ to $4 \%$ of all cancer cases $[18,33]$. In our material, dysplasia or carcinoma in lesions clinically corresponding to OL was found in 11 cases (5.29\%). This percentage is lower than that presented in the literature (15.6-39.2\%) [41]. These differences are probably caused by a non-homogenous classification of changes. Waldron and Shafer [42] analyzed retrospectively 3256 biopsies taken from changes corresponding to OL. Invasive cancer was found in 3.1\% of cases, carcinoma in situ or high-grade dysplasia in $4.6 \%$, while low-grade and moderate dysplasia in $12.2 \%$. In our study, this percentage was $1.92 \%, 0.96 \%, 2.88 \%$, respectively. In our study, the proportion of cancers developed on the basis of OL is lower (1.92\%) than in the literature reports (5-6\%) [18, 33]. There are interesting observations about the risk of OL malignancy. Within 5 years, neoplastic transformation on the basis of OL was observed in 7 patients (3.43\%). In 5 cases, patients did not start or discontinued treatment (12.2\%). In two cases, treatment was ineffective (1.4\%). This information suggests that treatment of $\mathrm{OL}$ reduces the risk of cancer. We observed less clinical progression of cancer among treated patients. This information is compatible with the literature, where malignant transformation of $\mathrm{OL}$ is estimated at $4-6 \%$ [33]. Our observations confirm the fundamental role of tobacco in the pathogenesis of oral cancer. All of patients with cancer were smokers. In the Uruguayan studies, De Stafani et al. [43] proved that the relative risk (RR) of oral cancer development among non-smokers was 1, while among smokers 4.2. The authors also found that the risk among people who have given up smoking is lower in comparison to active smokers (2.2 vs. 5.7). Merletti et al. [44] observed that the RR increases with the number of smoked cigarettes (from 4.4 to 6.2 ). Shiu et al. [45] conducted a cohort study of 
neoplastic transformation on the basis of OL in the Taiwanese population. The authors found that smoking and chewing betel predispose to the development of OL, while only betel is associated with malignant transformation. They also claimed that the abandonment of habits reduces the risk of $\mathrm{OL}$ and oral cancer [45]. Despite the extensive campaign, the problem of addiction to tobacco is extending, especially in developing countries. It is estimated that in 2000, 4.9 million people died from diseases connected with cigarette smoking, in 2020 it will be probably 10 million [46]. Unfortunately, the awareness of patients is insufficient, the vast majority of patients in our study did not discontinue or returned to the habit. It is difficult to predict the clinical behaviour and course of $\mathrm{OL}$. It is known that the probability of dysplasia correlates with morphology of lesions (especially with thickness). The risk of malignant transformation in the case of verrucous leukoplakia ranges from $70 \%$ to $100 \%$ [3, 18, 33]. The location of changes is significant. The most common places susceptible to malignant transformation are the floor of the oral cavity, bottom and side surfaces of the tongue, and soft palate [3, 18, 33, 42]. Our results show the highest percentage of malignant transformation within the floor of the mouth. Another prognostic factor may be molecular tests. It was proven that in the case of loss of heterozygosity ( $\mathrm{LOH}$ ) within chromosome $3 p$ and/ or $9 p$, the risk of malignant transformation increases 3.8 times, whereas the additional loss of loci 4q, 8p, 11q, 17p multiplies the risk 33 times. Genetic studies have proven that the process of carcinogenesis involves not only clinically visible change but is far wider [33].

\section{Conclusions}

Most of the patients were $50-70$ years old (average 58.1). The most common coexisting disease was diabetes. The OL predisposing factors were reported by $88 \%$ of the patients (tobacco smoking 50.49\%). There were $320 \mathrm{OL}$ lesions, and homogenous leukoplakia dominated (72.05\%). Multifocal OL was diagnosed in $58.2 \%$ of the patients. The most common lesion location was buccal mucosa (52.2\%). According to van der Waal's classification, most patients were classified as stage I and II. Malignant transformation on the basis of OL was diagnosed in 7 patients (3.43\%). The percentage of malignant transformation among untreated patients was $12.9 \%$, while among treated patients $-1.41 \%$. The highest risk of OSCC development was proven to be the floor of the mouth.

\section{References}

1. Warnakulasuriya S, Johnson NW, van der Waal I. Nomenclature and classification of potentially malignant disorders of the oral mucosa. J Oral Pathol Med 2007; 36: 575-80.

2. Pindborg JJ, Reichart PA, Smith CJ, van der Waal I. Histological typing of cancer and precancer of the oral mucosa.
International histological classification of tumours. World Health Organization 1997.

3. Reichart PA, Philipsen HP. Oral erythroplakia: a review. Oral Oncol 2005; 41: 551-61.

4. Shafer WG, Waldron CA. Erythroplakia of the oral cavity. Cancer 1975; 36: 1021-8.

5. Suter VG, Morger R, Altermatt HJ, et al. Oral erythroplakia and erythroleukoplakia: red and red-white dysplastic lesions of the oral mucosa - part 1: epidemiology, etiology, histopathology and differential diagnosis [German]. Schweiz Monatsschr Zahnmed 2008; 118: 390-7

6. Suter VG, Morger R, Altermatt HJ, et al. Oral erythroplakia and erythroleukoplakia: red and red-white dysplastic lesions of the oral mucosa-part 2: cytodiagnosis, pathogenesis, therapy, and prognostic aspects [German]. Schweiz Monatsschr Zahnmed 2008; 118: 510-8.

7. Gonzalez-Moles MA, Scully C, Gil-Montoya JA. Oral lichen planus: controversies surrounding malignant transformation. Oral Dis 2008; 14: 229-43.

8. Tilakaratne WM, Klinikowski MF, Saku T, et al. Oral submucous fibrosis: review on aetiology and pathogenesis. Oral Oncol 2006; 42: 561-8.

9. Awde JD, Kogon SL, Morin RJ. Lip cancer: a review. J Can Dent Assoc 1996; 62: 634-6.

10. Dufresne RG Jr, Curlin MU. Actinic cheilitis. A treatment review. Dermatol Surg 1997; 23: 15-21.

11. van der Waal I. Potentially malignant disorders of the oral and oropharyngeal mucosa: terminology, classification and present concepts of management. Oral Oncol 2009; 45: 31723.

12. Petti S. Pooled estimate of world leukoplakia prevalence: a systematic review. Oral Oncol 2003; 39: 770-80.

13. Petkowicz B, Skiba M, Tomaszewski T, Wysokińska-Miszczuk J. Leukoplakia in clinical and epidemiological aspect - analysis of cases [Polish]. Dent Med Probl 2004; 41: 635-41.

14. Dietrich T, Reichart PA, Scheifele C. Clinical risk factors of oral leukoplakia in a representative sample of the US population. Oral Oncol 2004; 40: 158-63.

15. Cabay RJ, Morton TH Jr, Epstein JB. Proliferative verrucous leukoplakia and its progression to oral carcinoma: a review of the literature. J Oral Pathol Med 2007; 36: 255-61.

16. van der Waal I, Axéll T. Oral leukoplakia: a proposal for uniform reporting. Oral Oncol 2002; 38: 521-6.

17. Warnakulasuriya S, Speight P, Epstein J. Diagnosing oral cancer: can toluidine blue mouthwash help? FDI World 1998; 7: 22-6.

18. Kaczmarek J. Precancerous lesions and precancerous conditions of squamous cell carcinomas of the upper aerodigestive tract [Polish]. Post Chir Głowy Szyi 2004; 2: 15-31.

19. Silverman S, Bhargava K, Smith LW, Malaowalla AM. Malignant transformation and natural history of oral leukoplakia in 55518 industrial workers of Gujarat, India. Cancer 1976; 38: 1790-5.

20. Axell T. Occurrence of leukoplakia and some other oral white lesions among 20333 adult Swedish people. Community Dent Oral Epidemiol 1987; 15: 46-51.

21. Hogewind WF, van der Waal I. Prevalence study of oral leukoplakia in a selected population of 1000 patients from the Netherlands. Community Dent Oral Epidemiol 1988; 16: 302-5.

22. Campisi G, Margiotta V. Oral mucosal lesions and risk habits among men in an Italian study population. J Oral Pathol Med 2001; 30: 22-8. 
23. Cebeci Al, Gulsahi A, Kamburoglu K, et al. Prevalence and distribution of oral lesions an adult Turkish population. Med Oral Patol Oral Cir Bucal 2009; 14: 272-7.

24. Tokajuk G, Stokowska W, Miksza-Żyłkiewicz R. Occurrence of lesions of the oral cavity mucosa among patients after 55 years old in North-Eastern region of Poland [Polish]. Gerontol Pol 2002; 10: 178-81.

25. Knychalska-Karwan Z. Disease lesions of oral cavity mucosa in 4752 patients treated in the Department of Restorative Dentistry, Medical University of Cracow in 1961-1998 [Polish]. Mag Stomatol 2004; 14: 10-4.

26. Field EA, Morrison T, Darling AE, et al. Oral mucosal screening as an integral part of routine dental care. Br Dent J 1995. 179: 262-6.

27. von Arx T, Koch S, Hardt N. Lesions of the mouth mucosa. An anamnestic and clinical study of 100 consecutive patients with mucosal lesions [German]. Schweiz Manatsschr Zahnmed 2002; 112: 326-9.

28. Bouquot JE, Gorlin RJ. Leukoplakia, lichen planus, and other oral keratoses in 23,616 white Americans over the age of 35 years. Oral Surg Oral Med Oral Pathol 1986; 61: 373-81.

29. Bizoń-Wróblewska M, Książek-Bąk H, Wojnar-Kalina A, et al. Occurrence of oral mucosal diseases in patients treated at out-patient clinic of Department of Conservative Dentistry and Periodontology of Silesia Medical Academy [Polish]. Stomatol Współcz 1997; 4: 283-9.

30. Banoczy J, Ginter Z, Dombi C. Tobacco use and oral leukoplakia. J Dent Educ 2001; 65: 322-7.

31. Morger R, Ramseier CA, Rees TD, et al. Oral mucosal findings related to tobacco use and alcohol consumption: a study on Swiss army recruits involving self-reported and clinical data. Oral Health Prev Dent 2010; 8: 143-51.

32. Górska R, Nowak M. Tobacco use as a risk factor of pathologic changes on oral mucous membrane [Polish]. Czas Stomatol 1997; 4: 261-4.

33. Kruk-Zagajewska A, Wierzbicka M. The tongue and floor of the mouth cancer - diagnosis and advances in treatment [Polish]. Contemp Onkol 2003; 7: 264-74.

34. Banoczy J, Rigo O. Prevalence study of oral precancerous lesions within a complex screening system in Hungary. Community Dent Oral Epidemiol 1991; 19: 265-7.

35. Maserejian NN, Joshipura KJ, Rosner BA, et al. Prospective study of alcohol consumption and risk of oral premalignant lesions in men. Cancer Epidemiol Biomarkers Prev 2006; 15: 774-81.

36. Albrecht M, Banoczy J, Dinya E, Tamas G Jr. Occurrence of oral leukoplakia and lichen planus in diabetes mellitus. J Oral Pathol Med 1992; 21: 364-6.

37. Auluck A. Diabetes mellitus: an emerging risk factor for oral cancer? J Can Dent Assoc 2007; 73: 501-3.

38. Sieńko E. The complex management of the oral leukoplakia [Polish]. Mag Stomatol 1998; 9: 45-50.

39. Sieńko E. Leukoplakia - precancerous lesions of mucosae membrane in the mouth [Polish]. Onkol Pol 1999; 2: 209-11.

40. Garcia-Pola Vallejo MJ, Martinez Diaz-Canel Al, Garcia Martin JM, et al. Risk factors for oral soft tissue lesions in an adult Spanish population. Community Dent Oral Epidemiol 2002; 30: 277-85.

41. Neville BW, Day TA. Oral cancer and precancerous lesions. CA Cancer J Clin 2002; 52: 195-215.

42. Waldron CA, Shafer WG. Leukoplakia revisited. A clinicopathologic study 3256 oral leukoplakias. Cancer 1975; 36: 1386-92.
43. De Stafani E, Boffetta P, Oreggia F, et al. Smoking patterns and cancer of the oral cavity and pharynx: a case control study in Uruguay. Oral Oncol 1998; 34: 340-6.

44. Merletti F, Bofetta P, Ciccone G, et al. Role of tobacco and alcoholic beverages in the etiology of cancer of oral cavity/ oropharynx in Torino, Italy. Cancer Res 1989; 49: 4919-24.

45. Shiu MN, Chen THH, Chang SH, Hahn LJ. Risk factors for leukoplakia and malignant transformation to oral carcinoma: a leukoplakia cohort in Taiwan. Br J Cancer 2000; 82: 1871-4.

46. Murray CJL, Lopez AD. Alternative projections of mortality and disability by cause 1990-2020: Global Burden of Disease Study. Lancet 1997; 349: 1498-504. 